\title{
TREK Channel Family Activator with a Well-Defined Structure-Activation Relationship for Pain and Neurogenic Inflammation
}

Yunguang Qiu, Lu Huang, Jie Fu, Chenxia Han, Jing Fang, Ping Liao, Zhuo Chen, Yiqing Mo, Peihua Sun, Daqing Liao, Linghui Yang, Jing Wang, Qiansen Zhang, Jin Liu, Feng Liu, Tingting Liu, Wei Huang, Huaiyu Yang ${ }^{*}$ \& Ruotian Jiang ${ }^{*}$

Table of Content

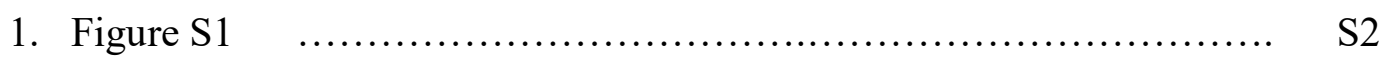

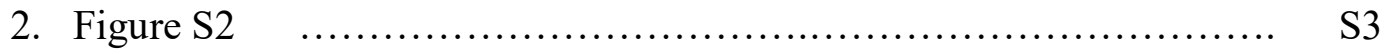

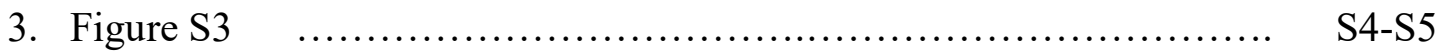

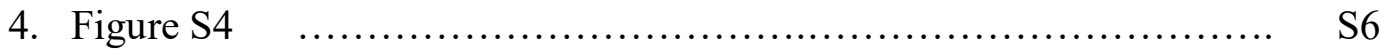

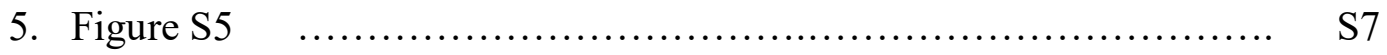

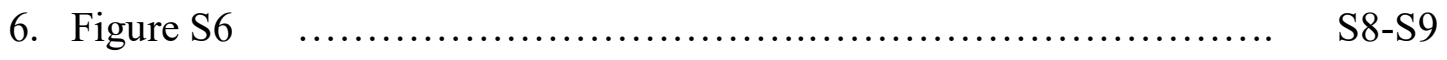

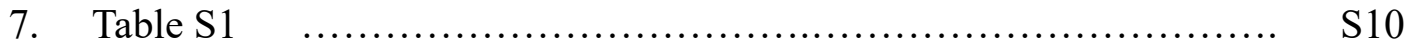

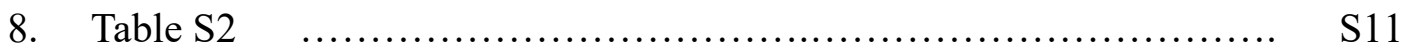

9. Data S1-S3 ................................................ S12 
A
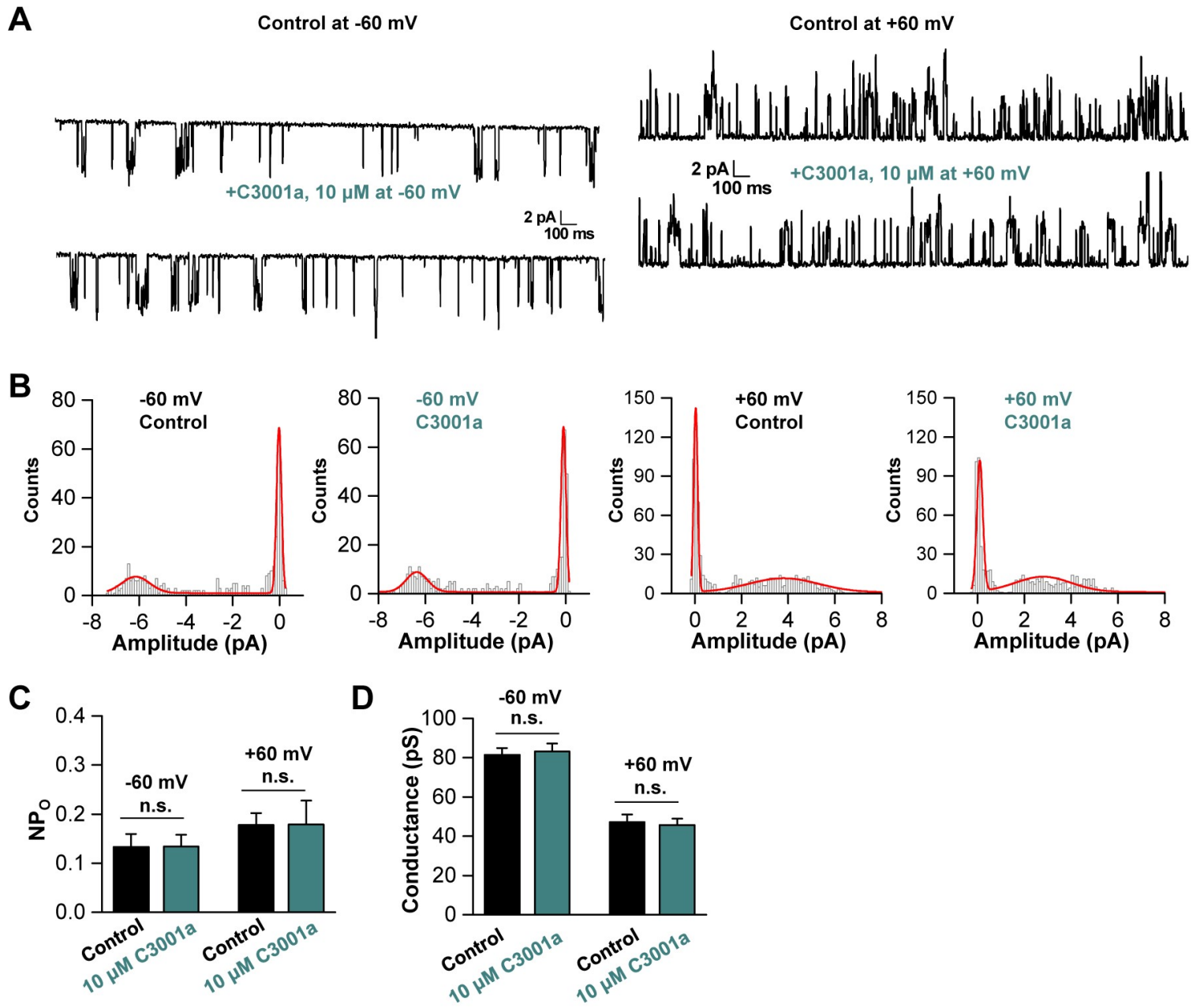

Figure S1. Inside-out recordings of TREK-1 with $10 \mu \mathrm{M}$ C3001a application. (A) Representative single-channel current traces from inside-out patches. (B) Amplitude histograms for the patch recording shown in (A) were fitted by Gaussian distributions. (C and $\mathrm{D}$ ) Analysis of $\mathrm{NP}_{\mathrm{o}}$ and channel conductance changes for the single-channel recordings ( $\mathrm{n}=5$; paired $t$ test). Data are shown as means \pm SEM. n.s., not significant. 



Figure S2. Representative current traces for several K2P channels in response to $10 \mu \mathrm{M}$ C3001a. 

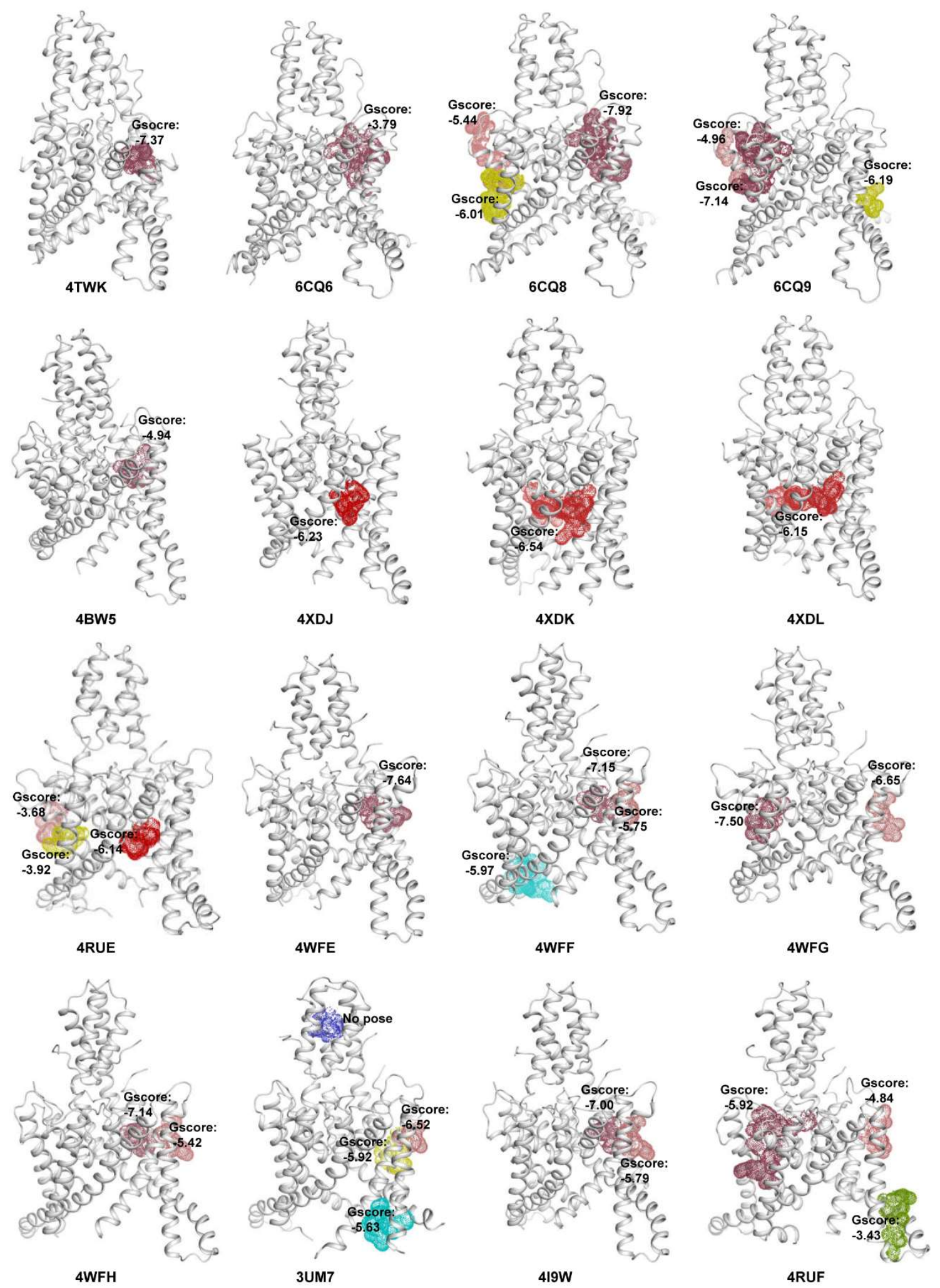
Figure S3. Pocket analysis of TREK channel crystal structures. A total of 16 crystal structures were used to explore potential druggability pockets. The best Gscores of C3001a docking into 32 druggable pockets were labeled. On the basis of the pockets position similarity, we divided 32 pockets into 7 groups, and each group were shown in different colors: red wine, red, pink, yellow, blue, cyan and splitpea. The P1-TM4 pocket (the cryptic binding site) is colored in red wine. Fpocket 2.0 server was adopted and pockets with druggability scores greater than 0.5 were considered as potential druggable pockets. 
A
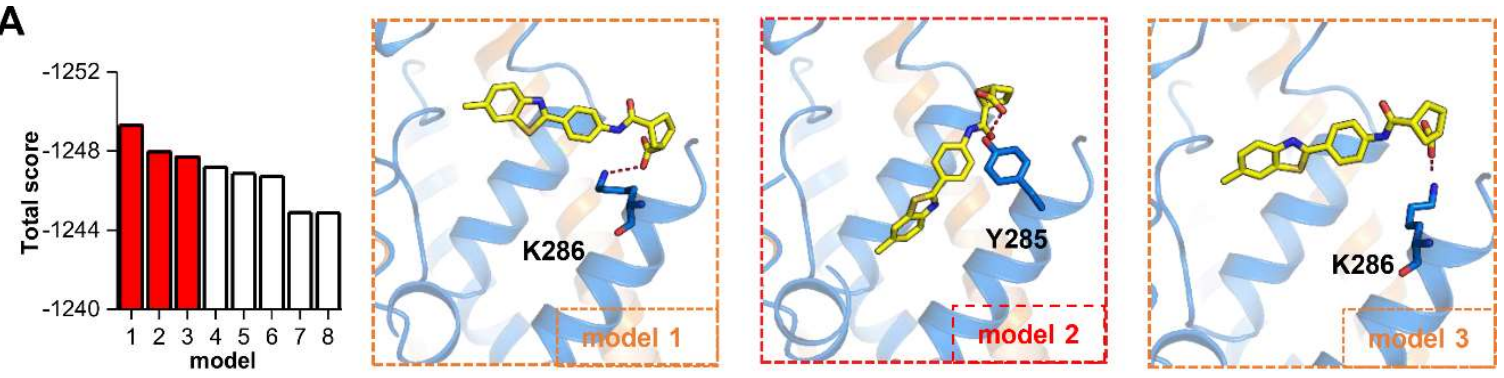

B

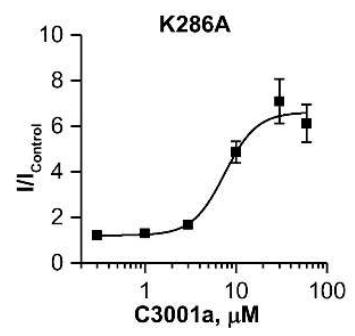

C

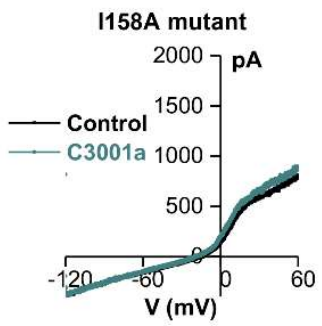

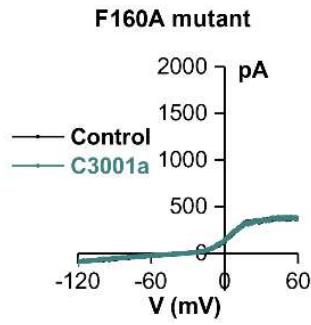

Figure S4. Possible binding models based on RosettaLigand docking and their validation.

(A) Total scores of eight possible binding modes and the three top-ranked binding models.

(B) Concentration-response curve of K286A mutant on C3001a activity with $\mathrm{EC}_{50}=8.44$

$\mu \mathrm{M}(\mathrm{n}=5-13) .(\mathrm{C})$ Representative traces of I158A and F160A mutants. Data are shown as means $\pm \mathrm{SEM}$. 

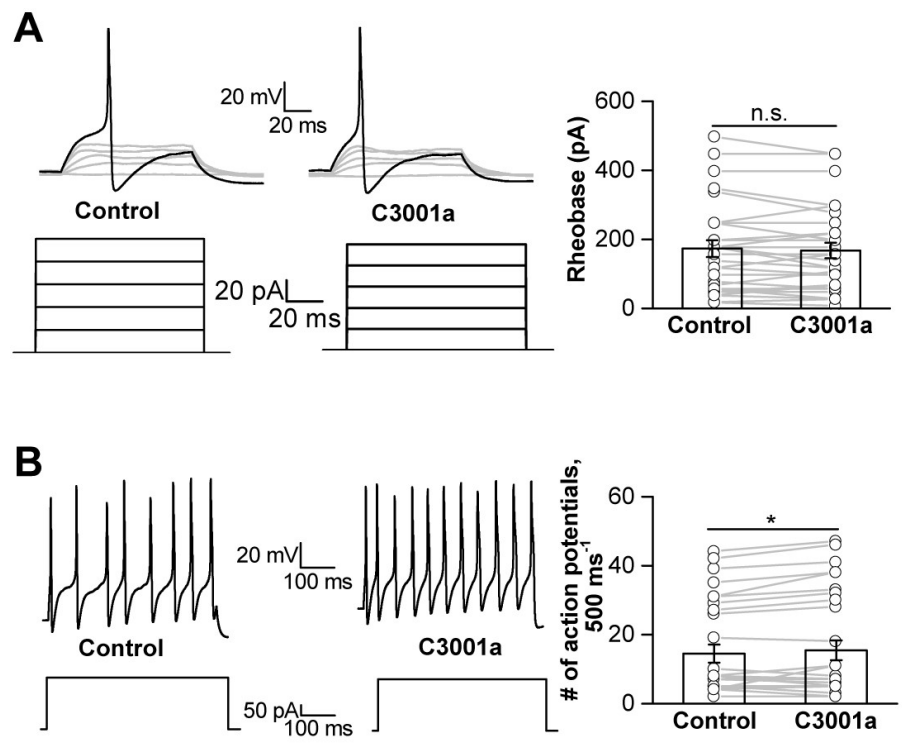

Figure S5. No inhibitory effects of C3001a on a portion of DRG neurons. (A) and (B) Traces and bar graph show the effects of C3001a on rheobase and firing frequency in nociceptive neurons [ $\mathrm{n}=29$ cells in four rats; Wilcoxon signed rank test in (A) and (B)]. Data are shown as means $\pm \mathrm{SEM} . * P<0.05$, and n.s., not significant. 
A

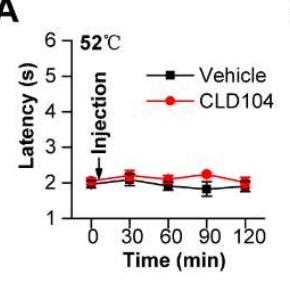

B
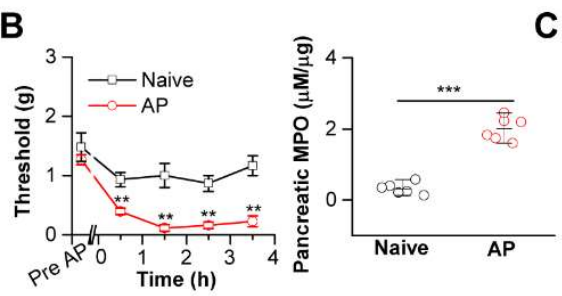

C
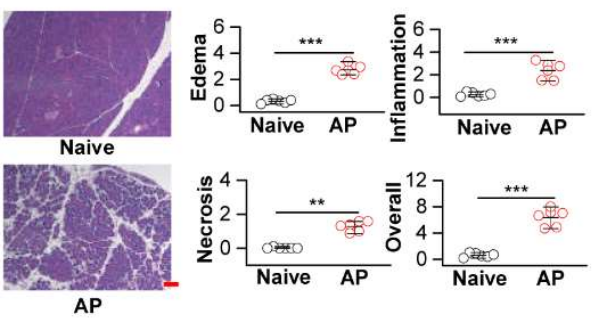
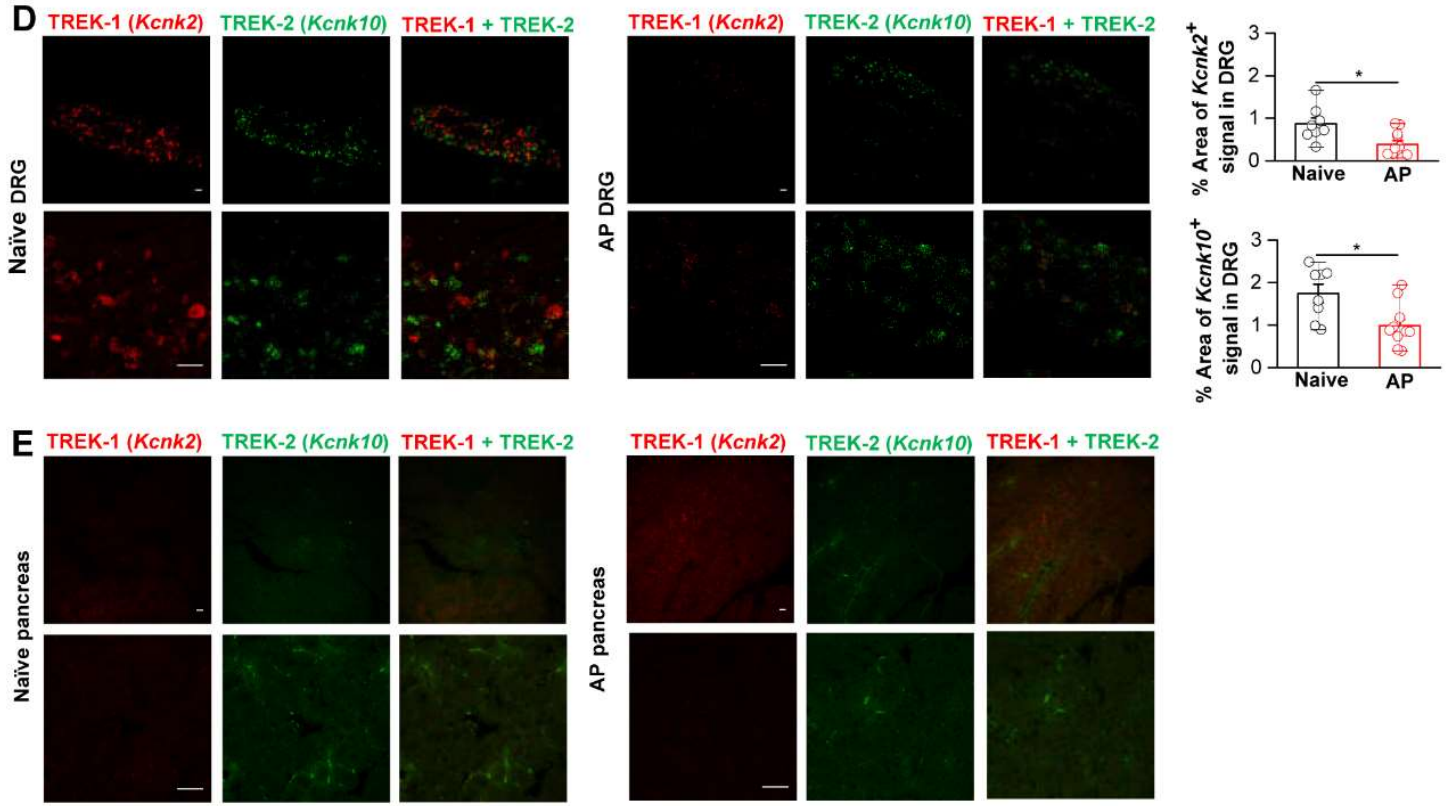

$\mathbf{F}$
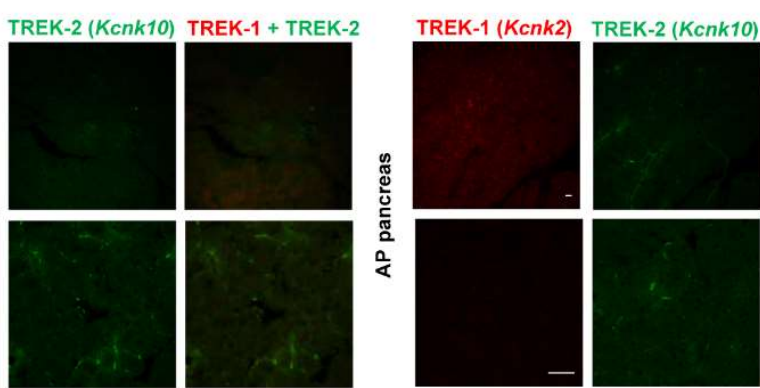

G

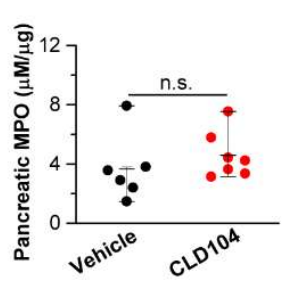

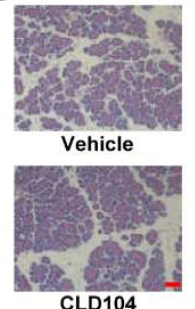
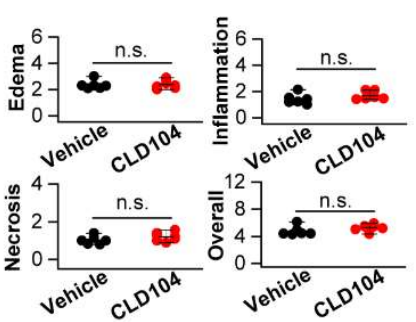

Figure S6. Data for nociception and AP associated with Figure 6. (A) Effects of CLD104 $\left(5 \mathrm{mg} / \mathrm{kg}\right.$ i.p.) on tail immersion test at $52{ }^{\circ} \mathrm{C}(\mathrm{n}=7-10$; unpaired $t$ test $)$; (B) The graph and scatter plots show the withdrawal thresholds (left) and MPO activity (right) in naïve and AP mice ( $\mathrm{n}=6$, unpaired $t$ test or Mann-Whitney test); (C) Representative images and scatter plots show pancreatic histopathological change and scores in naïve and AP mice ( $n=6$, unpaired $t$ test or Mann-Whitney test. Scale bar: $100 \mu m$ ); (D) Left, 
representative images show TREK-1 and TREK-2 mRNA expression in DRG in naïve and AP mice using RNAscope (Scale bar: $50 \mu \mathrm{m}$ ); right, quantifications for the expression of TREK-1 and TREK-2 $(\mathrm{n}=8-11$ sections, 3 mice, unpaired $t$ test); (E) Representative images show TREK-1 and TREK-2 mRNA expression in pancreas in naïve and AP mice using RNAscope (Scale bar: $50 \mu \mathrm{m}$ ). (F) Effects of CLD104 (10 $\mathrm{mg} / \mathrm{kg}$ i.p.) on MPO activity in AP mice ( $\mathrm{n}=6-7$, unpaired $t$ test). (G) Effects of CLD104 $(10 \mathrm{mg} / \mathrm{kg}$ i.p.) on pancreatic histopathological changes and scores in AP mice $(\mathrm{n}=6-7$, unpaired $t$ test or Mann-Whitney test. Scale bar: $100 \mu \mathrm{m}$ ). Data are shown as means \pm SEM. $* P<0.05, * * P<0.01,{ }^{* * *} P<0.001$, and n.s., not significant. 
Table S1. Pharmacokinetic profile of C3001a in plasma and brain following a single intraperitoneal administration to male mice.

\begin{tabular}{ccc}
\hline Dose & \multicolumn{2}{c}{ i.p. 5 mg/kg } \\
\cline { 2 - 3 } Tissue & Plasma & Brain \\
\hline $\mathrm{T}_{\text {max }}($ hour$)$ & 0.50 & 0.50 \\
$\mathrm{C}_{\text {max }}(\mathrm{ng} / \mathrm{ml})$ & 9255.00 & 48.92 \\
$\mathrm{AUC}_{0-\text { last }}(\mathrm{hr}$ (ng/ml) & 25181.78 & 208.96 \\
$\mathrm{~T}_{1 / 2}($ hour $)$ & 1.84 & 5.03 \\
& & 0.008
\end{tabular}

Abbreviations: $\mathrm{T}_{\max }$, time to $\mathrm{C}_{\max } ; \mathrm{C}_{\max }$, maximum plasma concentration; $\mathrm{AU} C$, area under the plasma or tissue concentration-time curve; $\mathrm{T}_{1 / 2}$, terminal half-life; NA, not applicable. 
Table S2. List of molecular formula strings.

I/IControl for TREK-1

Compound Name

SMILES

(Mean \pm SEM)

$(10 \mu \mathrm{M})$

\begin{tabular}{lll}
\hline $\mathrm{C} 3001 \mathrm{C} 1=\mathrm{CC}=\mathrm{C}(\mathrm{N}=\mathrm{C}(\mathrm{C} 2=\mathrm{CC}=\mathrm{C}(\mathrm{NC}([\mathrm{C} @ @ \mathrm{H}] 3 \mathrm{C}$ & $11.23 \pm 0.93$ \\
$\mathrm{C}[\mathrm{C} @ \mathrm{H}](\mathrm{C}(\mathrm{O})=\mathrm{O}) \mathrm{C} 3)=\mathrm{O}) \mathrm{C}=\mathrm{C} 2) \mathrm{S} 4) \mathrm{C} 4=\mathrm{C} 1$ & \\
$\mathrm{CLD} 104$ & $\mathrm{CC} 1=\mathrm{CC}=\mathrm{C}(\mathrm{N}=\mathrm{C}(\mathrm{C} 2=\mathrm{CC}=\mathrm{C}(\mathrm{NC}(\mathrm{C} 3 \mathrm{CCCC} 3)$ \\
& $=\mathrm{O}) \mathrm{C}=\mathrm{C} 2) \mathrm{S} 4) \mathrm{C} 4=\mathrm{C} 1$ \\
$\mathrm{CLD} 105$ & $\mathrm{CC} 1=\mathrm{CC}=\mathrm{C}(\mathrm{N}=\mathrm{C}(\mathrm{C} 2=\mathrm{CC}=\mathrm{C}(\mathrm{NC}([\mathrm{C} @ @ 0.01$ \\
$\mathrm{C}[\mathrm{C} @ \mathrm{H}](\mathrm{C}(\mathrm{OC})=\mathrm{O}) \mathrm{C} 3)=\mathrm{O}) \mathrm{C}=\mathrm{C} 2) \mathrm{S} 4) \mathrm{C} 4=\mathrm{C} 1$
\end{tabular}


Data S1. The binding model of C3001a/TREK-1 complex based on the TREK-1 structure with PDB code of 6CQ8.

Data S2. Homology model of the TRAAK channel based on the TREK-1 structure with PDB code of 6CQ8.

Data S3. Homology model of C3001a/TRAAK complex based on the TREK-1 structure with PDB code of 6CQ8. 